\title{
Forest Dwellers' Perception on Climate Change and Their Adaptive Strategies to Withstand Impacts in Mizoram, North-East India
}

\author{
Uttam Kumar Sahoo1*, Soibam Lanabir Singh1, Snehasudha S. Sahoo², \\ Lal Nundanga1, Lal Nuntluanga ${ }^{3}$, Angom S. Devi' ${ }^{3}$, John Zothansiama ${ }^{3}$ \\ ${ }^{1}$ Department of Forestry, Mizoram University, Aizawl, India \\ ${ }^{2}$ Indian Institute of Science Education \& Research, Kolkata, India \\ ${ }^{3}$ Department of Environmental Science, Mizoram University, Aizawl, India \\ Email: *uksahoo_2003@rediffmail.com, *uttams64@gmail.com, lanabir@gmail.com, sss17ms198@iiserkol.ac.in, \\ lalnundanga@rediffmail.com, tluanga249@rediffmail.com,john_229@yahoo.com, angom75@yahoo.com
}

How to cite this paper: Sahoo, U.K., Singh, S.L., Sahoo, S.S., Nundanga, L., Nuntluanga, L., Devi, A.S. and Zothansiama, J. (2018) Forest Dwellers' Perception on Climate Change and Their Adaptive Strategies to Withstand Impacts in Mizoram, North-East India. Journal of Environmental Protection, 9, 1372-1392. https://doi.org/10.4236/jep.2018.913085

Received: November 7, 2018

Accepted: December 10, 2018

Published: December 13, 2018

Copyright $\odot 2018$ by authors and Scientific Research Publishing Inc. This work is licensed under the Creative Commons Attribution International License (CC BY 4.0).

http://creativecommons.org/licenses/by/4.0/

(c) (i) Open Access

\begin{abstract}
We studied the perception of forest-dependent communities on climate change with its associated risk and their adaptation strategies in Mizoram, Northeast India. A total of 360 respondents (household heads) were randomly selected from 24 villages across the three different agro-climatic zones prevalent. The community perceived awareness of climate change phenomena in the region with a positive correlation between age, education and occupation of the respondents. The overall perception of climate change in temperature was medium (0.49), while low for change in precipitation (0.26) and seasonal durability (0.23). The community showed overall low score of perception on risk of climate change $(0.10)$ where risk on livelihood and socio-economic factors was higher than risk to environment or forest. Perception on impact of climate change was high for forest abiotic ecological factors (0.66) and flora and fauna (0.62), while medium on livelihood of forest-dependent communities (0.44). The majority (more than 75\%) of the respondents agreed that human beings are involved and responsible for climate change. Adoption of adaptive strategies to cope climate change ranged from 0.07 to 0.91 , amongst which zero tillage, use of traditional knowledge, forest fire prevention, soil and water conservation techniques, agroforestry practices and social forestry are popular. However, rain water harvesting and investments for crop insurance were adopted on low scores clearly implied by the educational and socio-economic status of the farmers in the majority. The study brings out the knowledge and perceptions to climate change by forest-dependent communities and their adaptive strategies to cope had been assessed. The
\end{abstract}


finding results seek the attention of researchers and policy makers to integrate technological and financial interventions in supporting farmer's effort to cope with climate change with a long term objective for improving their livelihood and climate sensitive resources at the same time.

\section{Keywords}

Perceptions, Climate Change, Adaptation, Forest Policy, Northeast India

\section{Introduction}

Climate change is generally recognized as a major issue having negative impacts on the earth's geological, biological and ecological systems. The trend of global warming has been observed at an increase in global average temperature by $0.8^{\circ} \mathrm{C}$ since 1900 [1]. Forest ecosystems are integral to the global biogeochemical cycles and act both as sources and sinks of greenhouse gases (GHGs), which exert significant influence on the earth's climate. Impacts of climate change on forests change tree species composition, growth and productivity [2], affecting changes in forest area and competition between species [3], and damage causing natural disturbances. It was also recognized that protective functions of forests get affected by climate change as well. Climate change is expected to exacerbate the vulnerability of forest tribes and communities especially with adverse impact on their livelihood [4] [5]. There are limited livelihood opportunities of the forest dwellers and marginal farmers [6] [7] [8] and therefore these people mostly draw on various non-timber forest products such as bamboo, cane/rattan, broom grass, anchiri (rhizome of Homalomena aromatica) and ethnomedicine related products for income generation. Forests are particularly sensitive to climate change, because the long life-span of trees depends on environmental stability. Unlike in agriculture, adaptation measures for forestry need to be planned well in advance expecting changes in the forests' growing conditions. Because the forests regenerated today will have to cope with the future climate conditions of at least several decades, often even for more than 100 years [9]. The impact of climate change on forest and biodiversity has recently become an issue of increasing importance [10]. Though there have been several reports on climate change on agriculture [11], studies pertaining to forest and biodiversity are somewhat limited.

Climate change not only directly affects the species diversity, but may also interacts with other human stressors especially in fragile/hilly ecosystems like Mizoram causing disruptions to food webs and other ecological services. It is believed that climate change affecting the forests will continue resulting in a change in many of the services that the forest ecosystem is able to provide. Once a decline in forest ecosystem services sets in, the ability of forest-dependent people to meet their basic needs for food, clean water and other necessities declines, deepening poverty, deteriorating public health and increasing social conflict [12] [13]. The forest dwellers, adjacent farmers and even considerable pro- 
portion of underprivileged population are particularly at risk due to climate change as they are dependent on its natural resources like forests for their livelihood, socio-economic and ecological well-being [14].

A great number of studies have been done on farm level adaptation to climate change across different countries [15]-[23]. In India, farmers' perception of climate change and their adaptation strategies are evident in works done on dry forests of Kalakad-Mundanthurai Tiger Reserve [24], two villages of Uttarakhand [25], in four villages of Maharasthra and Andhra Pradesh [26], in dry land Tamilnadu [27], in Chotanagpur plateau of eastern India [28], in Himalayan landscape [29] [30], West Bengal [31]. These studies reveal that farmers' adaptation strategies to climate change are depended on local resources and contexts. Considering the majority of livelihood proportion in rural areas, and continuously depends largely on climate-sensitive sectors, such as rain-fed agriculture, community based forest enterprises, dependence on non-wood forest products (NWFPs) among others, it is expected that the impact of climate change on forest-dependent communities of Mizoram will have serious livelihood problems.

Assessing the vulnerable and potential impacts of climate change on the forests and livelihood in Mizoram is therefore critical to its development and effective climate management measures. However, our understanding of deteriorating climate crisis and its impacts on the forest dwellers' livelihood, their perception and adaptation strategies are inadequate, whose understanding will provide a better location specific insights and generate additional information for relevant policy and decision making. Despite advances in physical and biological research, assessment of climate change form a socio-economic perspective is essential to prepare a roadmap for capacity building of local communities for effective adaptation and mitigation strategies. Therefore, an attempt was made in this study to identify perception and other socio-economic factors influencing adaptation strategies that are pursued by the forest-dependent communities in response to climate variability and adaptability. Besides, the study aims to identify the coping and adaptation measures adopted by communities within different agro-climatic zones in Mizoram.

\section{Materials and Methods}

\subsection{Study Sites}

The state of Mizoram covers an area of 21,087 $\mathrm{km}^{2}$ accounting for only $0.64 \%$ of the total geographical area of India. Mizoram is classified as one location in the "Eastern Himalayan Region" experiencing high rainfall, heavy soil erosion and floods but having high forest cover. The State is further divided into three sub-agro-climatic zones, viz., Humid Mild Tropical Hill Zone, Humid Subtropical Hill Zone and Humid Temperate Subalpine Zone. The study in order to assess the impact of climate change on forest and livelihood in Mizoram was undertaken in 24 selected villages in eight districts comprise under the three dif- 
ferent agro-climatic zones of Mizoram (Figure 1, Table 1). The State of Mizoram experienced cyclonic storms, cloudbursts, hailstorms and landslides annually owing to its geo-climatic conditions. Mizoram receives abundant rainfall during monsoon period but long dry spells in post monsoon and steep hillsides results in minimum underground water retention leading to dry perennial water sources. Traditional slash and burn cultivation accompanied with uncontrolled fire also aggravated the situation causing ecological imbalances. During the past decades from 1951 to 2017, Mizoram observed an annual rise in temperature by $0.01^{\circ} \mathrm{C}$ (Table 2) mainly attributed by mean maximum temperature increasing @ $0.03^{\circ} \mathrm{C}$ per annum. No trend was detected in the mean minimum temperature. The increasing trend thus indicates a further rise in the heat wave in years

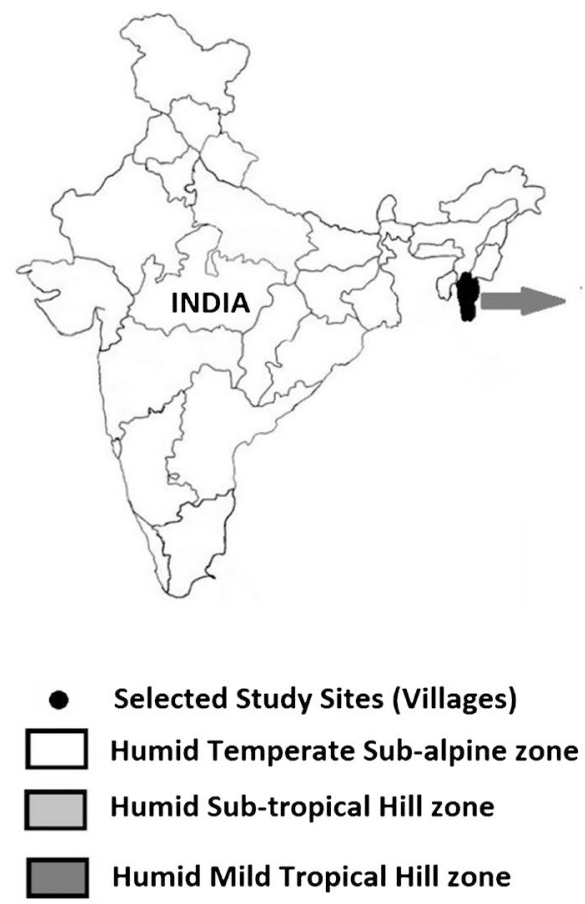

Humid Mild Tropical Hill zone

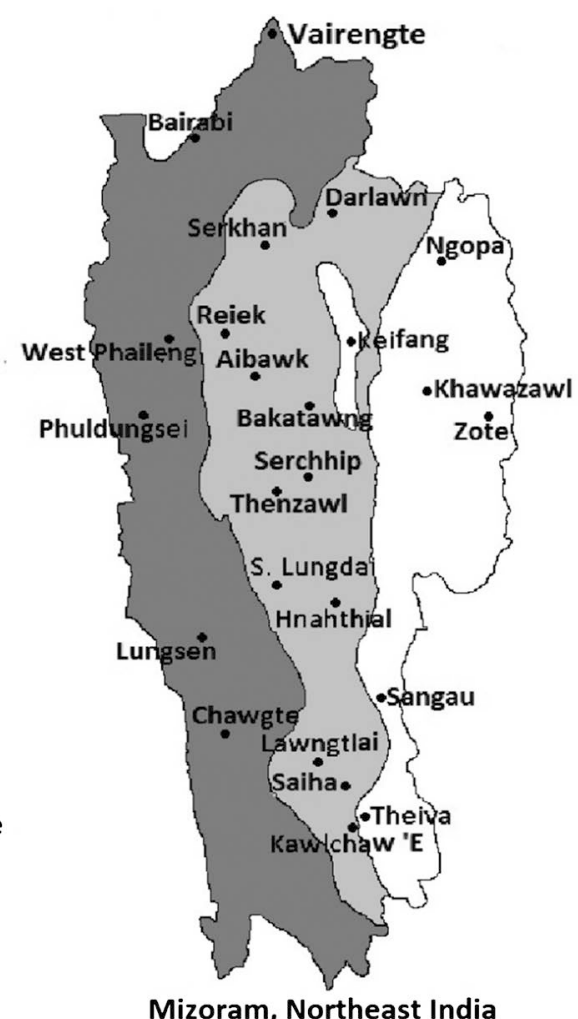

Mizoram, Northeast India

Figure 1. Study sites and demarcation of different agro-climatic zones of Mizoram.

Table 1. Geographic and characteristic features of Agro climatic zones in Mizoram.

\begin{tabular}{|c|c|c|c|c|c|}
\hline Sl. No. & $\begin{array}{l}\text { Agro-Climatic Zone \& Altitude } \\
\text { Range (amsl) }\end{array}$ & $\begin{array}{l}\text { Average Rainfall } \\
\quad(\mathrm{mm} / \mathrm{yr})\end{array}$ & $\begin{array}{l}\text { Mean Temperature } \\
\quad(\text { Max-Min) }\end{array}$ & Area $\left(\mathrm{Km}^{2}\right)$ & Study Villages Selected \\
\hline 1. & $\begin{array}{l}\text { Humid Mild Tropical Hill Zone } \\
\text { (less } 800 \mathrm{~m} \text { ) }\end{array}$ & $2000-3000$ & $30-12{ }^{\circ} \mathrm{C}$ & $\begin{array}{c}14,733 \\
(69.87 \%)\end{array}$ & $\begin{array}{l}\text { Vairengte, Bairabi, West Phaileng, } \\
\text { Phuldungsei, Lungsen, Chawgte }\end{array}$ \\
\hline 2. & $\begin{array}{l}\text { Humid Mild Sub-Tropical Hill } \\
\text { Zone }(800-1400 \mathrm{~m})\end{array}$ & $2500-3000$ & $30-12{ }^{\circ} \mathrm{C}$ & $\begin{array}{c}5581 \\
(26.47 \%)\end{array}$ & $\begin{array}{l}\text { Darlawn, Serkhan, Reiek, Aibawk, } \\
\text { Bakatawng, Serchhip, Thenzawl, S. Lungdai, } \\
\text { Hnahthial, Lawngtlai, Kawlchaw 'E, Saiha }\end{array}$ \\
\hline 3. & $\begin{array}{l}\text { Humid Temperate Sub-Alpine } \\
\text { Zone (1400 m more) }\end{array}$ & $2000-3000$ & $20-11^{\circ} \mathrm{C}$ & $\begin{array}{c}773 \\
(3.67 \%)\end{array}$ & $\begin{array}{c}\text { Ngopa, Keifang, Zote, Khawzawl, Sangau, } \\
\text { Theiva }\end{array}$ \\
\hline
\end{tabular}


to come. The rainfall trend in Mizoram shows an annual increasing trend $(+0.33$ $\mathrm{mm} / \mathrm{yr})$ greatly contributed by change in monsoon rainfall $(+7.71 \mathrm{~mm} / \mathrm{yr})$ followed by summer rainfall $(+2.80 \mathrm{~mm} / \mathrm{yr})$. Post monsoon and winter rainfall show a decreasing trend. Rainfall in Mizoram during May-August has increased while rainfall during the other months in a year has showed a decreasing rainfall departure trend (Figure 2). Based on interpretation of satellite data, the forest cover of the state is $18,186 \mathrm{~km}^{2}$ ( $86.27 \%$ of total state geographical area) with 131 $\mathrm{km}^{2}$ covered with dense forest, $5861 \mathrm{~km}^{2}$ covered with moderately dense forest and $12,194 \mathrm{~km}^{2}$ with open forest in terms of forest canopy density classes. The state of Mizoram witnessed a decrease in forest cover area from $19,240 \mathrm{~km}^{2}$ in 2009 to $18,186 \mathrm{~km}^{2}$ in 2017 owing to deforestation and land use changes with maximum total forest cover change rate during 2015-17 (Figure 3).

\subsection{Data Collection}

Hypothesizing that mean temperature and precipitation would vary across agro-climatic zones across the state, which may have some impact on the outcome of

Table 2. Seasonal changes in climate of Mizoram between 1951-2017.

\begin{tabular}{cccccc}
\hline Seasonal Trends (1951 to 2017) & Annual & Winter & Summer & Monsoon & $\begin{array}{c}\text { Post } \\
\text { Monsoon }\end{array}$ \\
\hline Mean Maximum Temperature $\left({ }^{\circ} \mathrm{C} / \mathrm{yr}\right)$ & $+0.03^{*}$ & $+0.04^{*}$ & $+0.01^{*}$ & $+0.05^{*}$ & $+0.05^{*}$ \\
Mean Minimum Temperature $\left({ }^{\circ} \mathrm{C} / \mathrm{yr}\right)$ & No trend & No trend & $-0.01^{*}$ & No trend & No trend \\
Mean Temperature $\left({ }^{\circ} \mathrm{C} / \mathrm{yr}\right)$ & $+0.01^{*}$ & $+0.02^{*}$ & No trend & $+0.02^{*}$ & $+0.02^{*}$ \\
Mean Diurnal Temperature Range $\left({ }^{\circ} \mathrm{C} / \mathrm{yr}\right)$ & $+0.04^{*}$ & $+0.04^{*}$ & $+0.02^{*}$ & $+0.04^{*}$ & $+0.06^{*}$ \\
Rainfall (mm/yr) & +0.33 & -0.31 & +2.80 & +7.71 & -6.19 \\
\hline
\end{tabular}

Note: Increasing (+) and decreasing (-) trends significant at $95 \%$ level of significance are marked with " $*$ ” sign (compiled from source [32] and additional data set from published sources).

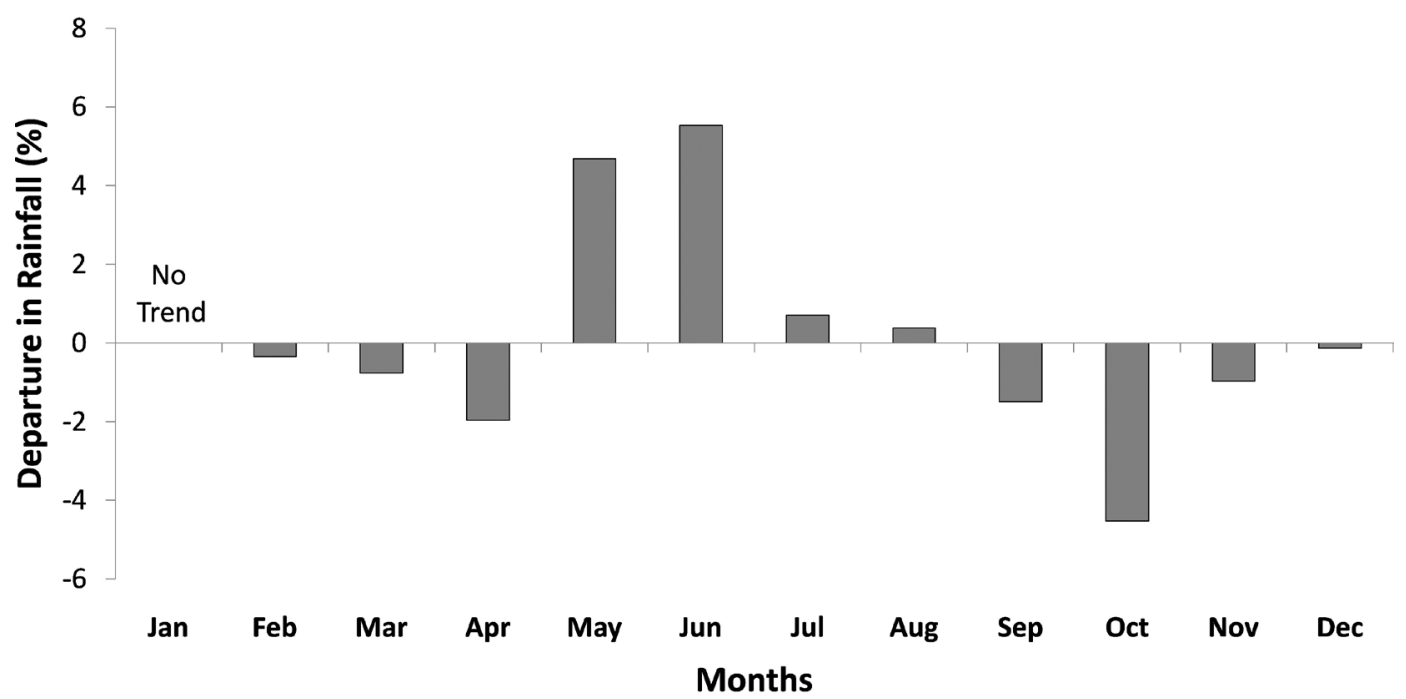

Figure 2. Monthly rainfall departure trend in Mizoram for 1951-2017 (compiled from source [32] and additional data from published sources). 


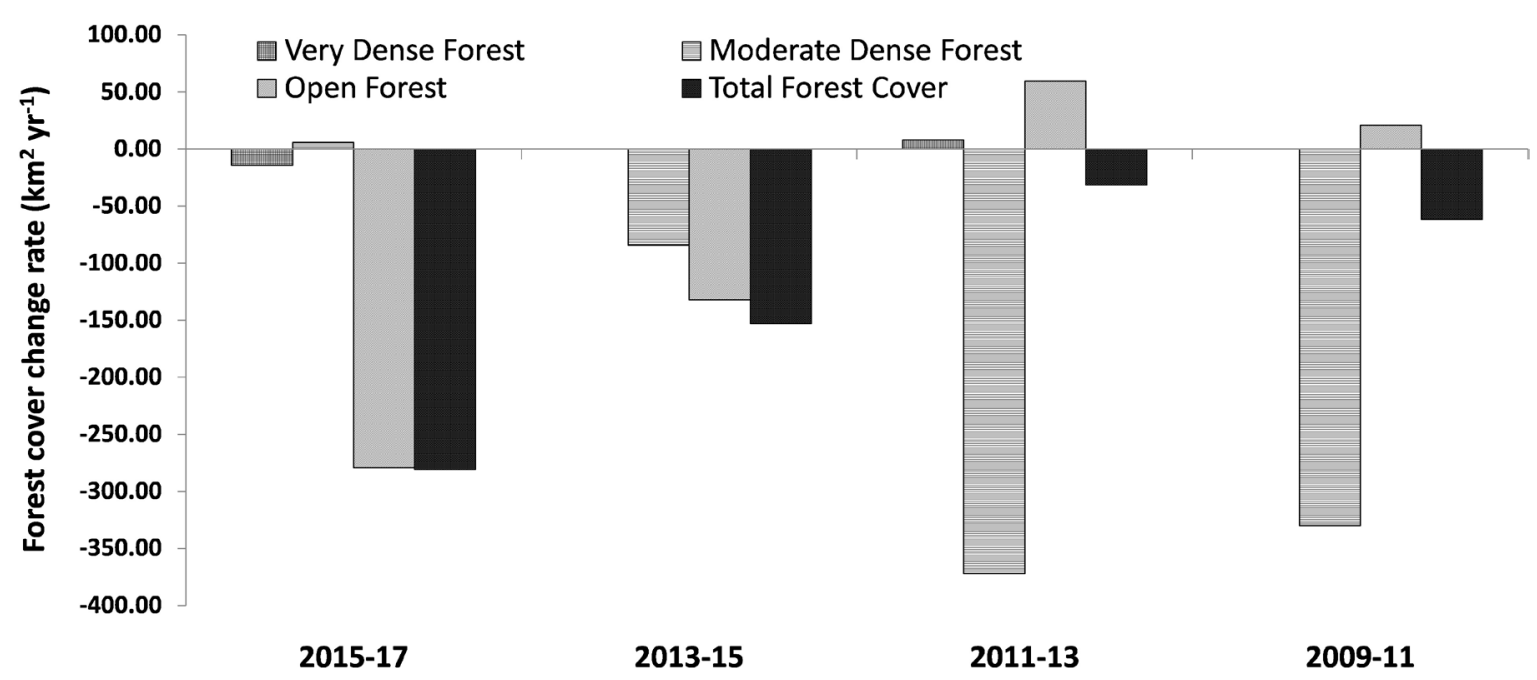

Figure 3. Forest cover change rate in different forest types in Mizoram (compiled from source [33]).

the study; it was decided to select study villages from different districts in the state and cover all the three agro-climatic zones (Table 1). A total of 24 villages (6 in tropical, 12 in sub tropical and 6 in temperate sub alpine zone) were selected for the study. Secondary data was obtained by reviewing literature from both published and unpublished sources. Reconnaissance survey and primary data collection was done in all 24 selected villages across the three agro-ecological zones during 2017-18. The primary data were collected through structured interviews using questionnaires [34] and interviews were conducted face-to-face in a very friendly environment. Additional information was gathered from key informants through focus group discussions. Purposive sampling method was used for selection of the area under study, and random sampling method was used for selection of the respondents. To ensure adequate representation, the selection of respondents was done randomly taking 15 heads/households in each of the twenty four selected villages. A total of three hundred and sixty respondents were interviewed. The representative of the sample was initially tested using descriptive statistics to see the mean, mean and variance differences, stochastic dominance if any.

Pre-tested well structured close ended personal interview schedule was designed. The questionnaire included the socio-economic profile of the respondents like age, gender, education, occupation, awareness about phenomena related to climate change, perception of the impact of climate change on forest ecosystem, perception of the impact of climate change on livelihood and adopted measures related to climate change. The knowledge questions were tested against the responses of "yes" (1) and "no" (0) indicating that the respondent having or not having awareness/knowledge on the specific question. The opinion statements were tested against a three point Likert scale [35] with responses of "agree" (+1), "undecided" (0) and "disagree" $(-1)$. The adaptation practices were assessed against a three point Likert scale with 0,1 and 2 scores for responses of "don't know", "not adopted" and "adopted", respectively. 


\subsection{Statistical Analysis}

The collected data from questionnaires were processed, classified and tabulated. Both descriptive (frequency, per cent, mean, and standard error) and analytical (correlation) statistics were performed using Microsoft EXCEL 2007 and SPSS (Version 17). Pearson correlation was calculated between various demographic attributes and the respondents' awareness level on knowledge of climate change across all the 24 villages adjacent to the forests.

\section{Results and Discussion}

\subsection{Demographic Attributes and Awareness Level on Climate Change}

Demographic attributes of the study population (360 respondents) in 24 villages across three agro-climatic zones in Mizoram are presented in Table 3. In all agro-climatic zones, more than $50 \%$ of the respondents occur in the age groups of 30 - 40 and 40 - 50 years. Maximum respondents had secondary level (41.1\%)

Table 3. Demographic attributes of the study population $(n=360)$.

\begin{tabular}{|c|c|c|c|c|}
\hline Attributes & ACZ-I & ACZ-II & ACZ-III & Average \\
\hline \multicolumn{5}{|l|}{ Gender } \\
\hline Male & $42(46.67 \%)$ & 97 (53.89\%) & $48(53.33 \%)$ & 187 (51.9\%) \\
\hline Female & $48(53.33 \%)$ & $83(46.11 \%)$ & $42(46.67 \%)$ & $173(48.1 \%)$ \\
\hline \multicolumn{5}{|l|}{ Age Groups } \\
\hline $20-30$ & $11(12.2 \%)$ & $18(10.0 \%)$ & $7(7.8 \%)$ & $36(10.0 \%)$ \\
\hline $30-40$ & $26(28.9 \%)$ & $49(27.2 \%)$ & $17(18.9 \%)$ & $92(25.6 \%)$ \\
\hline $40-50$ & $21(23.3 \%)$ & $42(23.3 \%)$ & $32(35.6 \%)$ & $95(26.4 \%)$ \\
\hline $50-60$ & $16(17.8 \%)$ & $27(15.0 \%)$ & $25(27.8 \%)$ & $68(18.9 \%)$ \\
\hline $60-70$ & $13(14.4 \%)$ & $39(21.7 \%)$ & $9(10.0 \%)$ & $61(16.9 \%)$ \\
\hline $70-80$ & $3(3.3 \%)$ & $5(2.8 \%)$ & $0(0.0 \%)$ & $0(2.2 \%)$ \\
\hline \multicolumn{5}{|l|}{ Education } \\
\hline Primary & $33(36.7 \%)$ & $42(23.3 \%)$ & $20(22.2 \%)$ & $95(26.4 \%)$ \\
\hline Secondary & $29(32.2 \%)$ & $82(45.6 \%)$ & 37 (41.1\%) & $148(41.1 \%)$ \\
\hline College & $22(24.4 \%)$ & $44(24.4 \%)$ & $23(25.6 \%)$ & $89(24.7 \%)$ \\
\hline University & $6(21.4 \%)$ & $12(6.7 \%)$ & $10(11.1 \%)$ & $28(7.8 \%)$ \\
\hline \multicolumn{5}{|l|}{ Occupation } \\
\hline Farmer & $39(43.3 \%)$ & $69(38.3 \%)$ & $34(37.8 \%)$ & $142(39.4 \%)$ \\
\hline Labour & $25(27.8 \%)$ & $51(28.3 \%)$ & $16(17.8 \%)$ & $92(25.6 \%)$ \\
\hline Business & 17 (18.9\%) & $36(20.0 \%)$ & $25(27.8 \%)$ & $78(21.7 \%)$ \\
\hline Govt. Employee & $9(10.0 \%)$ & $24(13.3 \%)$ & $15(16.7 \%)$ & $48(13.3 \%)$ \\
\hline
\end{tabular}

ACZ-I: Humid Mild Tropical Hill Zone; ACZ-II: Humid Mild Sub-tropical Hill Zone; ACZ-III: Humid Temperate Sub-alpine Hill Zone. 
of education while number of respondents with the highest educational qualification was the least (7.8\%). Majority of the respondents were farmers $(39.4 \%)$ followed by labour (25.6\%) and business (921.7\%), and the least section were government employee (13.3\%). In all agro-climatic zones studied, all the 360 respondents acknowledged the phenomenal changes in climate over the year (Table 4) and revealed that majority (52. 8\%) of the respondents had medium awareness score followed by high awareness score (28.6\%) and rest had low awareness score (18.6\%). Maximum respondents (\%) for low, medium and high awareness level of climate change was observed in Humid Mild tropical Hill zone $(21.11 \%)$, Temperate Sub-alpine Zone (56.7\%) and Humid Mild Sub-tropical Hill Zone (31.1\%) respectively. Majority of the respondents agreed changes in temperature (61.4\%); forest structure, composition and function (53.6\%) with increased incidence of pests and diseases in forest (51.7\%). However, a major portion of the respondents did not understand and were new to the statements regarding climate change awareness such as environmental pollution $(30.3 \%)$ and variations in seasonal durability (32.8\%). In all the agro-climatic zones, knowledge on climate change was fairly medium with an average score of 4.31 out of 8 (Table 5). It was observed that the level of awareness vary significantly among the different age groups, however it did not differ significantly between the agro-climatic zones. Oldest respondents had an awareness level of 6.62 and the least in youngest group (2.53). Average awareness level values in low, medium and high categories were 2.00, 3.96 and 6.44 respectively out of 8 . Relationship between various demographic attributes and level of awareness

Table 4. Awareness level score (out of 8 statements) on knowledge of climate change in different agro climatic zones of the study population.

\begin{tabular}{ccccc}
\hline Attributes & ACZ-I & ACZ-II & ACZ-III & Average \\
\hline Age Groups & & & & \\
$20-30$ & $2.64 \pm 0.30$ & $2.33 \pm 0.24$ & $2.85 \pm 0.38$ & $2.53 \pm 0.15^{\mathrm{a}}$ \\
$30-40$ & $2.88 \pm 0.20$ & $3.00 \pm 0.14$ & $2.94 \pm 0.24$ & $2.96 \pm 0.09^{\mathrm{a}}$ \\
$40-50$ & $3.86 \pm 0.22$ & $4.05 \pm 0.15$ & $4.06 \pm 0.18$ & $4.01 \pm 0.12^{\mathrm{b}}$ \\
$50-60$ & $5.25 \pm 0.25$ & $5.59 \pm 0.19$ & $5.72 \pm 0.20$ & $5.56 \pm 0.12^{\mathrm{c}}$ \\
$60-70$ & $6.08 \pm 0.28$ & $6.26 \pm 0.16$ & $5.78 \pm 0.33$ & $6.15 \pm 0.12^{\mathrm{d}}$ \\
$70-80$ & $6.67 \pm 0.58$ & $6.60 \pm 0.44$ & No Respondents & $6.62 \pm 0.18^{\mathrm{d}}$ \\
Awareness Level & & & & \\
Low (<3) & $2.00 \pm 0.00$ & $2.00 \pm 0.00$ & $2.00 \pm 0.00$ & $2.00 \pm 0.00^{\mathrm{a}}$ \\
Medium (3 to 5) & $3.84 \pm 0.11$ & $3.98 \pm 0.08$ & $4.06 \pm 0.12$ & $3.96 \pm 0.58^{\mathrm{b}}$ \\
High (>5) & $6.45 \pm 0.11$ & $6.45 \pm 0.07$ & $6.40 \pm 0.10$ & $6.44 \pm 0.05^{\mathrm{c}}$ \\
Total (1 to 8) & $4.09 \pm 0.17$ & $4.37 \pm 0.13$ & $4.39 \pm 0.17$ & $4.31 \pm 0.09^{\mathrm{d}}$ \\
\hline
\end{tabular}

\pm Standard error of Mean; different letters a, b, c, d indicate significant differences at $\mathrm{p}<0.05$; ACZ-I: Humid Mild Tropical Hill Zone; ACZ-II: Humid Mild Sub-tropical Hill Zone; ACZ-III: Humid Temperate Sub-alpine Hill Zone. 
among the population study is depicted in Figure 4. Significant positive correlations were observed between age, educational and occupational groups with the level of awareness. Though, not significant, the level of awareness was negatively correlated with gender groups indicating female have less awareness than males in the study population.

Climate change is nevertheless a global environmental threat. Northeast India in general and Mizoram in particular is much less developed but having diverse agro-climatic zones and hilly terrain compared to the mainland India and thus, the region as a whole is prone to different kinds of climatic shocks. All climatic

Table 5. Distribution of respondent on the basis of different awareness statements of climate change in the study population $(\mathrm{n}=360)$.

\begin{tabular}{|c|c|c|c|c|}
\hline & ACZ-I & ACZ-II & ACZ-III & Average \\
\hline \multicolumn{5}{|c|}{ Level of awareness (out of 8 awareness statements) } \\
\hline Low $(<3)$ & $19(21.1 \%)$ & $34(18.9 \%)$ & $14(15.6 \%)$ & $67(18.6 \%)$ \\
\hline Medium (3 to 5$)$ & $49(54.4 \%)$ & $90(50.0 \%)$ & $51(56.7 \%)$ & $190(52.8 \%)$ \\
\hline $\operatorname{High}(>5)$ & $22(24.4 \%)$ & $56(31.1 \%)$ & $25(27.8 \%)$ & $103(28.6 \%)$ \\
\hline \multicolumn{5}{|c|}{ Climate change awareness statements } \\
\hline Change in temperature & $56(62.2 \%)$ & $114(63.3 \%)$ & $51(56.7 \%)$ & $221(61.4 \%)$ \\
\hline Late onset of monsoon & $49(54.4 \%)$ & $65(36.1 \%)$ & $46(51.1 \%)$ & $160(44.4 \%)$ \\
\hline Change in rainfall & $45(50.0 \%)$ & $84(46.7 \%)$ & $26(28.9 \%)$ & $155(43.1 \%)$ \\
\hline Variation in seasonal durability & $14(15.6 \%)$ & $56(31.1 \%)$ & $48(53.3 \%)$ & $118(32.8 \%)$ \\
\hline Change in forest structure & $65(72.2 \%)$ & $89(49.4 \%)$ & $39(43.3 \%)$ & $193(53.6 \%)$ \\
\hline Increase in diseases and pest & $19(21.1 \%)$ & $125(69.4 \%)$ & $42(46.7 \%)$ & $186(51.7 \%)$ \\
\hline Global warming & $49(54.4 \%)$ & $89(49.4 \%)$ & $35(38.9 \%)$ & $173(48.1 \%)$ \\
\hline Environmental pollution & $12(13.3 \%)$ & $56(31.1 \%)$ & $41(45.6 \%)$ & $109(30.3 \%)$ \\
\hline
\end{tabular}

ACZ-I: Humid Mild Tropical Hill Zone; ACZ-II: Humid Mild Sub-tropical Hill Zone; ACZ-III: Humid Temperate Sub-alpine Hill Zone.

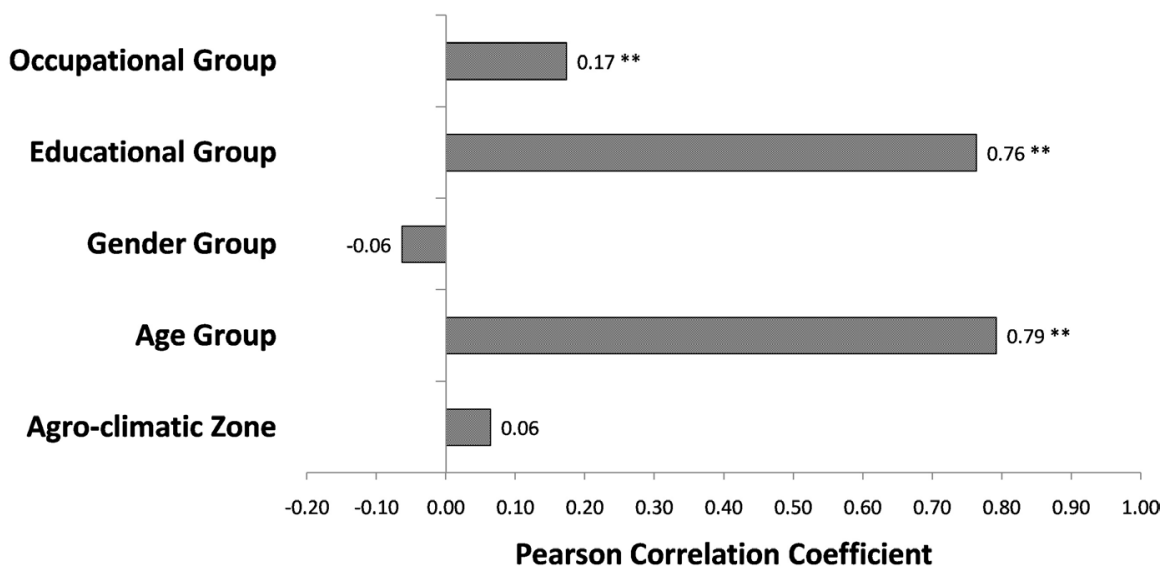

Figure 4. Pearson correlation coefficient of various demographic attributes with the awareness level on statements of climate change in the study population. Values with ${ }^{\star *}$ indicate significance at $\mathrm{p}<0.05$. 
variability observed over time, like many other places could nevertheless be attributed to human activity directly or indirectly [36]. All the respondents were aware of climate change though with different levels (low, medium and high) and significant positive correlation with the age and education. Similar studies also reported that education had significantly impacted the perception on climate change [37] implying that climate change happenings might have different perceptions with variations in educations, all things being equal. Higher and technical education brings about exposure to new areas and access to information on improved technologies; hence more awareness campaigns needs to be organized as more than $60 \%$ of the respondents were only up to secondary level. Awareness and educational exposure trainings also need to be focused on lower age groups as the level of awareness is low to medium in respondents aged below 60 years, and moreover, they form the most vulnerable section of stakeholders not ready to negotiate/address climate change mitigation and adaptation in years to follow.

In the present study most concerns were raised by forest dwellers on climatic variability are increasing temperature, irregularity in rainfall, dry spell during summer and decreasing winter. Similar observations have been observed by farmers' elsewhere [38] [39] [40]. Majority of the respondents have no doubt in believing that human activity is playing significant role in climate change [41] and the level of perception is related to education [42]. We, however, encountered a variation in perception across the agro-climatic zones, the lowest level of perception for humid mild tropical zone. Like many other reports, majority of the farmers' opined increased temperature bring changes to forest composition and increased incidents of pests and diseases. Climate also impacted health, crop and livestock and forest dwellers' income. However, they are unwilling to move out of the forest believing that nature as savior [31]. The perception of the respondents on decrease of forest area match with the Forest Survey of India records [33]. The causes of decrease in forest and woodland cover were perceived to be population pressure and increasing demand for fuel wood and construction materials. This implies that there will be decrease in forest products such as wood and NTFPs and forage. The decrease in forest cover would negatively impact the environment and reduce the ecosystem services such as soil and water conservation ability, carbon stock, pollination services etc. [43]. Increasing run-off, as a result of intense but short duration rainfall, is causing poor accumulation of water in soil, thereby resulting in the drying up of water pools [30]. Early ripening of crops is observed by these people, which is consistent with early onset of flowering and growing season; and further proliferation of weeds and pests are simultaneously observed in wild plants both by the local people and scientists [29].

\subsection{Forest Dwellers' Perception of Climate Change}

Overall perception of the forest dwellers vis-à-vis events due to change in tem- 
perature is medium as the score is 0.49 (Figure 5). This is because $85 \%$ of the respondents perceived increase in average day and night temperature including mildness in winter (76.1\%) and warming of winds (61.9\%). However, the overall perception of the community of the change in precipitation related phenomena and of the change in regularity and duration of seasonal events is low with average perception scores of 0.26 and 0.23 respectively (Figure 5). But when considering some individual statements related to change in precipitation, interestingly almost all the respondents believed that rainfall get unpredictable day by day $(85.0 \%)$ with changed intensity and pattern $(76.1 \%)$ but generally arriving late $(92.2 \%)$ and withdrawing early $(71.9 \%)$ over the past few decades. Considering the individual statements relating to abnormalities of seasons, it is found that almost all of the respondents apprehended (more than $80 \%$ ) climate related hazards like unpredictable seasons and believed that droughts, floods and dry spells have increased with proportionate decrease in the duration of winter. The current perception of the villagers of climate change impacts compared to the past 5 years is presented in Figure 6. Majority of the respondents perceived increase in the intensity of sun's heat (84.2\%), followed by increased frequency of river drying up (65.7\%) and increase in incidence of human diseases $(64.3 \%)$. Also, a majority of the respondents perceived a decrease in intensity of rainfall (40.6\%). Based on the average perception score of 0.10 after assigning scores to different risk perception statements, it is found that the level of perception of the community is low (Table 6) as majority of the people in developing countries have limited knowledge of physical processes leading to climate change [44]. The community's perception on livelihood and socio-economic risks were higher than on risk to environment or forest. Perception scores with high risk as a result of climate change were observed in increasing poverty with reduced income

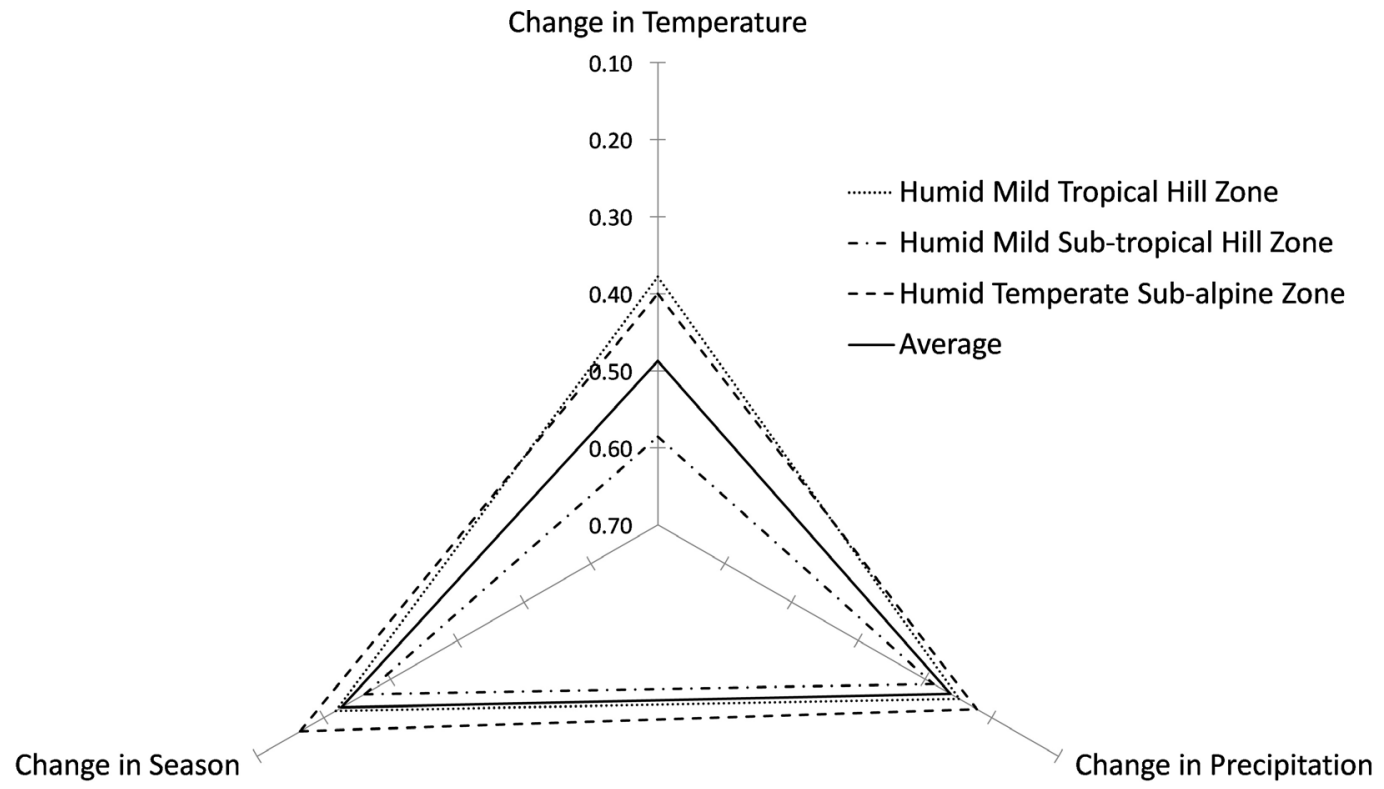

Figure 5. Respondent's perception in change in climatic parameters. 


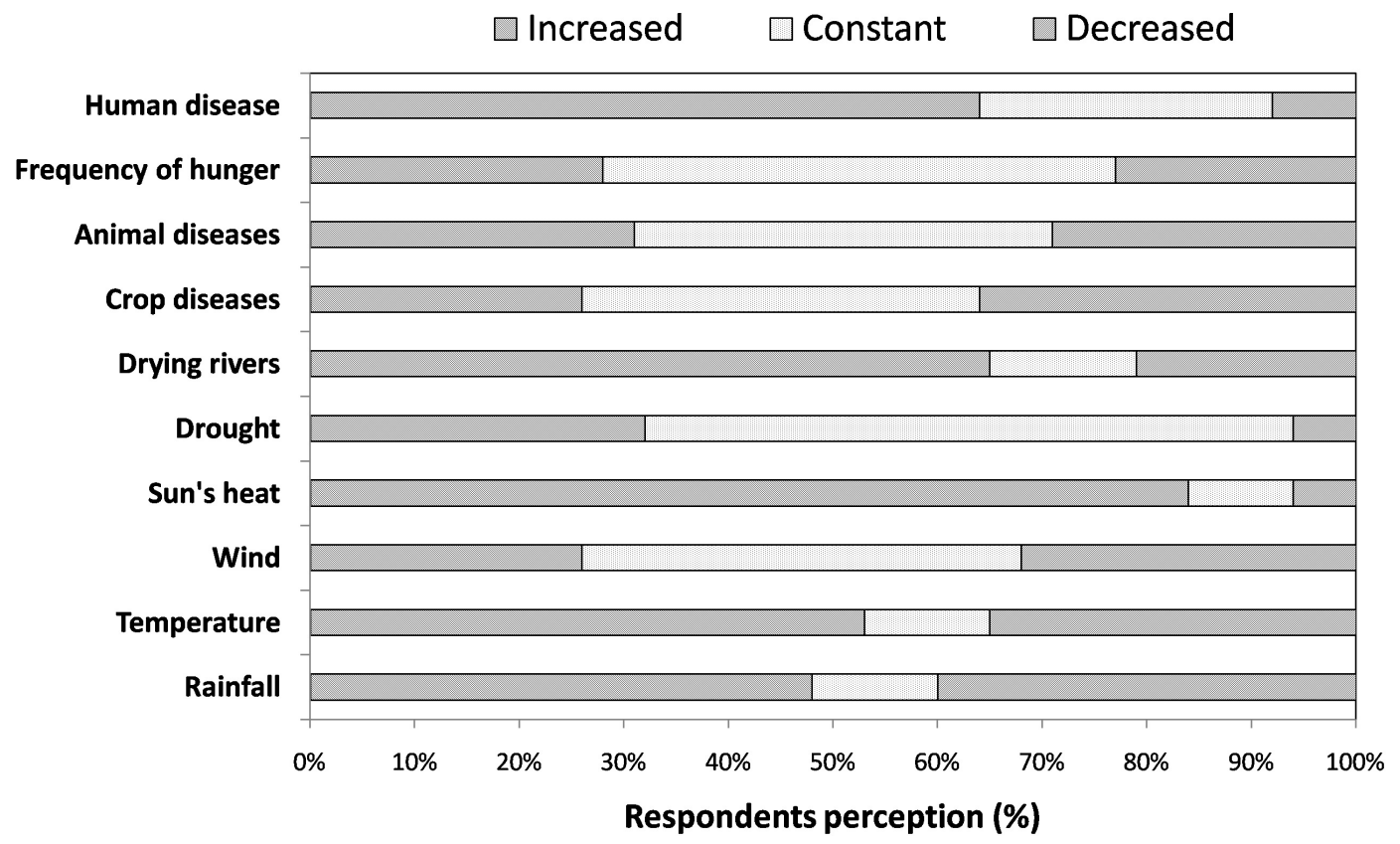

Figure 6. Perceptions on impacts of climate change compared to last 5 years.

Table 6. Perception on risk of climate change by respondents in different agro climatic zones of the study population.

\begin{tabular}{ccccc}
\hline & ACZ-I & ACZ-II & ACZ-III & Average \\
\hline Perception on risk of climate change & & & & \\
Heavy inundation of forest land & -0.40 & -0.35 & -0.41 & -0.38 \\
Affect the livelihood of people & 0.89 & 0.89 & 0.89 & 0.89 \\
Decline in standard of living & -0.24 & -0.18 & -0.34 & -0.24 \\
Occurrence of food shortage and starvation & -0.48 & -0.41 & -0.30 & -0.40 \\
Increase in suffering from serious diseases & 0.54 & 0.60 & 0.66 & 0.60 \\
Catastrophic impact on forest biodiversity & 0.44 & 0.52 & 0.59 & 0.52 \\
Migration of people and animal & -0.74 & -0.73 & -0.76 & -0.74 \\
Social inequality between rich and poor & 0.72 & 0.89 & 0.38 & 0.72 \\
Increase in poverty with reduced income & 0.93 & 0.89 & 0.96 & 0.92 \\
$\quad$ Increase in superstitious belief in God & -0.82 & -0.86 & -0.86 & -0.85 \\
$\quad$ Average Mean Score & 0.08 & 0.13 & 0.08 & 0.10 \\
\hline
\end{tabular}

ACZ-I: Humid Mild Tropical Hill Zone; ACZ-II: Humid Mild Sub-tropical Hill Zone; ACZ-III: Humid Temperate Sub-alpine Hill Zone.

(0.92), affecting livelihood (0.89) and creating social inequality between rich and poor (0.72). Respondents also associated risk of climate change on personal level with increase susceptibility of serious disease $(0.60)$ as reported by studies from other developing countries [45]. However, respondents believed climate change will not lead to increase in superstitious belief in God $(-0.85)$; no one will migrate from their forest lands $(-0.74)$; and starvation will not occur $(-0.40)$. This 
clearly defines the indigenous people perceptions of love for their land, forest and their ecosystem as a whole and belief in the nature as their savior, whereby they express unwillingness to leave their land and migrate to earn or live in a foreign land. Respondents also perceived the threat potential that climate change will might bring catastrophic impacts on biodiversity (0.52) while there may not be heavy inundation of forest land $(-0.38)$.

\subsection{Impact of Climate Change on Forest Resources and Biodiversity}

The level of perception on impact of climate change on forest ecology in terms of abiotic ecological factors, flora and fauna records average score between 0.66 and 0.62 respectively. And the impact of climate change on livelihood of forest-dependent communities is medium whose average perception score is 0.44 (Table 7). Considering the specific impact statements on forest abiotic ecological factors, high impacts were observed in decrease in forest area cover (0.68), decrease in flow of streams/river (0.78), quick drying of water bodies (0.81) and quick drying of seasonal streams (0.87). Climate change had medium impacted the intensity of flash flood (0.49), decreased forest litter (0.50), decreased soil fertility (0.51) and increased soil erosion (0.61). Climate change highly impacted forest flora and fauna regarding to early ripening of fruits/seeds (0.69), changes in tree phenology (0.76), increased incidence of weed invasion (0.78) and change/decrease in fish species in forest river (0.84), whereas medium impact were observed in decrease in pollinator population (0.31), increase in mortality (0.40), decrease in forest biodiversity (0.55) and increase in insects, pests and diseases (0.62). Majority of the respondents perceived that climate change highly impacted their livelihood in terms of decrease in fish catch (0.90); increase in livelihood dependency on forest (0.78) and decrease in quantity fodder collection (0.73). Climate change had medium impact on livelihood by reduced intensity of grazing (0.48) and decrease in collection of ethno-medicinal plants (0.44). However, the villagers responded a merge perceived decrease in collection of fuel wood (0.03), NWFPs (0.06) and edible forest products (0.11) as it was considered forest is the only source that fulfils people's domestic energy needs and other requirements since these resources were traditionally freely accessible to them. The future availability of various resources would nevertheless be determined by the degree of climate change [10].

\subsection{Adaptation Response to Climate Change}

Based on the survey, $31.9 \%$ of the respondents opined climate change is caused partly by nature and partly by human, followed by entirely human (30.3\%) and mainly human (17.5\%) as presented in Figure 7. A quarter of the respondents (24.7\%) showed no concern of climate change, while the remaining showed concerned in the order: very much concerned $(46.7 \%)>$ fairly concerned $(25.5 \%)>$ concerned $(3.1 \%)$. Considering the adaptive capacity based on awareness-adoption mean scores of each adaptation options (0.07 - 0.91), the adaptive 
capacity while responding to climate change is at medium level with average mean score of 0.69 (Table 8). High level of adoption were observed with the adoption of zero tillage practices (0.91), indigenous traditional knowledge for insect control (0.90), forest fire prevention activities (0.88), per-monsoon dry

Table 7. Perception on impact of climate change by respondents in different agro climatic zones of the study population.

\begin{tabular}{|c|c|c|c|c|}
\hline & ACZ-I & ACZ-II & ACZ-III & Average \\
\hline \multicolumn{5}{|c|}{ Impact of climate change on forest abiotic ecological factors } \\
\hline Decrease in forest area cover & 0.60 & 0.62 & 0.88 & 0.68 \\
\hline Increase in soil erosion & 0.46 & 0.67 & 0.63 & 0.61 \\
\hline Decrease in forest litter over the years & 0.33 & 0.52 & 0.63 & 0.50 \\
\hline Decrease in forest soil fertility & 0.59 & 0.42 & 0.59 & 0.51 \\
\hline Decrease in flow of stream/rivers & 0.73 & 0.74 & 0.88 & 0.78 \\
\hline Increase in intensity of flash flood & 0.56 & 0.53 & 0.36 & 0.49 \\
\hline Quick drying of seasonal stream & 0.81 & 0.98 & 0.71 & 0.87 \\
\hline Quick drying of water bodies after rain & 0.76 & 0.96 & 0.54 & 0.81 \\
\hline Average Mean Score & 0.60 & 0.68 & 0.65 & 0.66 \\
\hline \multicolumn{5}{|l|}{ Impact of climate change on forest flora and fauna } \\
\hline Change/decrease in fish species in the river & 0.66 & 0.93 & 0.83 & 0.84 \\
\hline Increase in insects, pest and diseases & 0.58 & 0.74 & 0.41 & 0.62 \\
\hline Increase in plant and animal mortality & 0.39 & 0.43 & 0.36 & 0.40 \\
\hline Decrease in overall forest biodiversity & 0.41 & 0.60 & 0.60 & 0.55 \\
\hline Early ripening of forest fruit/seed & 0.76 & 0.78 & 0.43 & 0.69 \\
\hline Changes in tree phenology & 0.83 & 0.73 & 0.74 & 0.76 \\
\hline Increase in incidence of weed invasion & 0.80 & 0.74 & 0.82 & 0.78 \\
\hline Decrease in populations of pollinators & 0.32 & 0.28 & 0.37 & 0.31 \\
\hline Average Mean Score & 0.59 & 0.65 & 0.57 & 0.62 \\
\hline \multicolumn{5}{|c|}{ Impact of climate change on livelihood of forest-dependent communities } \\
\hline Decrease in fish catch from seasonal streams & 0.96 & 0.87 & 0.91 & 0.90 \\
\hline Increase in livelihood dependency on forest & 0.72 & 0.80 & 0.81 & 0.78 \\
\hline Decrease in quantity of NWFPs collection & -0.13 & 0.16 & 0.04 & 0.06 \\
\hline Decrease in quantity of fuel wool collection & -0.03 & 0.14 & -0.14 & 0.03 \\
\hline Decrease in quantity of fodder collection & 0.64 & 0.77 & 0.74 & 0.73 \\
\hline Decrease in collection for ethno-medical plants & 0.53 & 0.31 & 0.61 & 0.44 \\
\hline Decrease in collection of edible forest products & -0.02 & 0.11 & 0.24 & 0.11 \\
\hline Reduced intensity of animal grazing in forest & 0.51 & 0.36 & 0.71 & 0.48 \\
\hline Average Mean Score & 0.40 & 0.44 & 0.49 & 0.44 \\
\hline
\end{tabular}

NWFPs: Non-wood forest products; ACZ-I: Humid Mild Tropical Hill Zone; ACZ-II: Humid Mild Sub-tropical Hill Zone; ACZ-III: Humid Temperate Sub-alpine Hill Zone. 


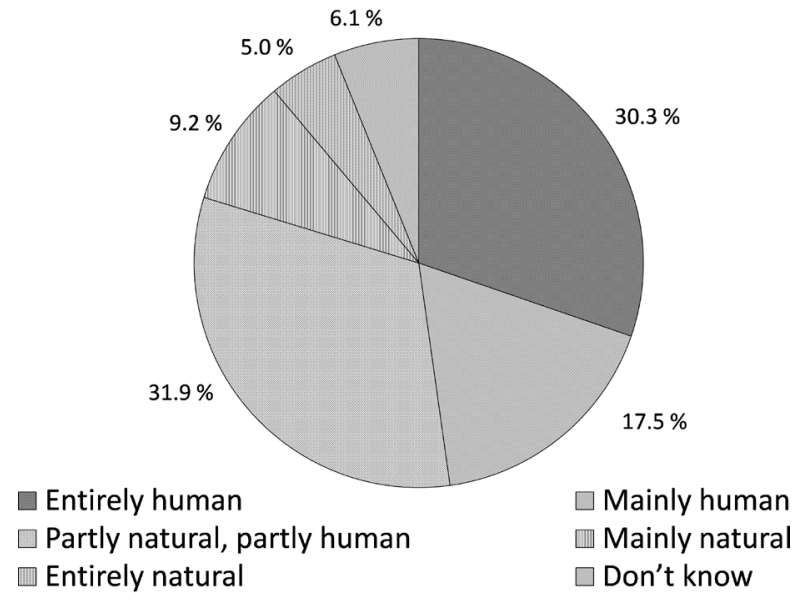

Figure 7. Distribution of respondents' opinion (\%) responsible for climate change.

Table 8. Distribution of respondents according to knowledge-adoption statements.

\begin{tabular}{|c|c|c|c|c|}
\hline & ACZ-I & ACZ-II & ACZ-III & Average \\
\hline \multicolumn{5}{|l|}{ Possible strategies to cope with crop failure } \\
\hline Dry seeding prior to monsoon & 0.92 & 0.84 & 0.87 & 0.87 \\
\hline Adoption of agroforestry practices & 0.64 & 0.82 & 0.78 & 0.77 \\
\hline Adoption of crop rotation practices & 0.73 & 0.68 & 0.68 & 0.69 \\
\hline Changing farm operations timings & 0.38 & 0.34 & 0.33 & 0.35 \\
\hline Adoption of intercropping practices & 0.58 & 0.62 & 0.66 & 0.62 \\
\hline Mulching practices & 0.86 & 0.94 & 0.91 & 0.91 \\
\hline Rain water harvesting & 0.44 & 0.45 & 0.46 & 0.45 \\
\hline Zero tillage practices & 0.91 & 0.91 & 0.92 & 0.91 \\
\hline Use of short duration crop varieties & 0.73 & 0.72 & 0.81 & 0.75 \\
\hline Use of drought tolerant crop varieties & 0.59 & 0.60 & 0.54 & 0.58 \\
\hline Adoption of soil conservation techniques & 0.91 & 0.75 & 0.83 & 0.81 \\
\hline Use of water conservation techniques & 0.82 & 0.81 & 0.78 & 0.80 \\
\hline Insect control through traditional knowledge & 0.89 & 0.89 & 0.94 & 0.90 \\
\hline Control disease, insects and pest with chemicals & 0.63 & 0.62 & 0.66 & 0.63 \\
\hline Adoption of social forestry activities & 0.82 & 0.69 & 0.63 & 0.71 \\
\hline Forest fire protection activities & 0.87 & 0.88 & 0.91 & 0.88 \\
\hline Investments for crop insurance & 0.05 & 0.08 & 0.07 & 0.07 \\
\hline Average Mean Score & 0.69 & 0.68 & 0.69 & 0.69 \\
\hline
\end{tabular}

ACZ-I: Humid Mild Tropical Hill Zone; ACZ-II: Humid Mild Sub-tropical Hill Zone; ACZ-III: Humid Temperate Sub-alpine Hill Zone.

seeding (0.87), water conservation techniques $(0.83)$, soil conservation techniques (0.81), adoption of agroforestry practices (0.77), use of short duration crop varieties (0.75) and social forestry activities (0.71). Medium level of adoption were observed with crop rotation practices (0.69), chemical control of insect 
pest and diseases (0.63), inter cropping practices (0.62) and use of drought tolerant crop varieties (0.58). Low level of adoption were observed in rain water harvesting (0.45), change in time of farm operations (0.35) and crop insurance (0.07). Amid all adaptation strategies to cope climate change, the concept of crop insurance was not largely known to the majority of the respondents (86.7\%) followed by that of change in time of farm operations (61.9\%) while the other options were known to above $60 \%$ of the respondents.

It is equally important to assess the risks and their management by the community after evaluating the perceptions of climate change, as the study can further provide important guidelines for designing and implementing adaptive responses and policies [19] [20]. Based on the wide varying adaptive capacity responses (0.07 to 0.91 ), the forest-dependent communities have adopted one or a combination of adaptation options. Individual attitudes to risk, policy and institutional barriers are factors to influence decision making vis-a-vis climate change adaptation, despite the degree and scope of scientific awareness are made available [46]. Average adaptive capacity of the farmers in all agro-climatic zones to cope climate change is medium which might be due to their continued dependence on natural resources and constrains in socio-economic sectors [47] [48]. However, indigenous farming knowledge and technology may help in conserving natural resources and combating climate change [43] [49] [50]. Agroforestry and perennial plantations could be major strategies to combat climate change and also by enhancing resistant approaches to climate impacts on the forest dwelling communities. Agroforestry has double potential to address climate change issues: for example greenhouse gas mitigation strategies to be adopted through carbon sequestration and sustainable adjustment to changing conditions [16]. As most of the respondents were farmers and had very low income with poor economic conditions, they lack expertise despite their willingness to adapt to the effects of climate change. This could be the reason which farmers avoid to adopt some strategies in spite having awareness considering the involvement of financial investments and technical knowhow. This fact clearly indicates institutional interventions are necessary for capacity building facilities such as trainings, in field demonstrations, financial support and appropriate policy by the government. This will bring about a sustainable human environment interaction aimed with suitable adaptation strategies and improve livelihood. North-east India in general and Mizoram in particular has been lacking in effective climate change and adaptation related policies particularly for forestry sectors. Besides, the state has a very low technological and financial capacity in adapting to climate change. Nevertheless farmers' have been coping using their traditional methods [26]. However, these are not sufficient. Forest dwellers' knowledge about perception and adaptation may be used to compliment specific policies to address their concerns and for a long term planning for climate sensitive resources. Diversified livelihood options should be explored through indigenous agroforestry farming methods integrated with animals for 
income generation, food production and social security. On the basis of local perceptions reported, adaptive measures should be formulated regarding cropping patterns, phenology and shift in distributional range of species and human diseases. Forest resources should be effectively managed with strategies that address land degradation, loss of biodiversity and ecosystem services which will both adapt to anticipate climatic conditions and valued by local communities.

\section{Conclusion}

Forest is the most important land use in Mizoram occupying over $86.27 \%$ geographical area of the state. It provides numerous supporting, provisioning, regulating and cultural services to mankind. In view of the fact that climate change is a reality and together with the existing socio-economic processes such as ongoing shifting cultivation, deforestation, forest fragmentation and other form of habitat loss, population growth, urbanization etc. as unignorable facts, climate change would lead to significant change in the delivery of such services. The increasing temperature, changes in rainfall patterns, more intense and frequently occurring extreme events will continue to affect the future service provisions and livelihoods depended on forests. Some site specific impacts of climate change involving non-commercial products are expected to produce additional stresses on people having limited adaptive capacity. Forest structure is changing at a faster rate, many of the mixed and broadleaved forests are being now converted to single storied bamboo forests causing destruction of habitat to wildlife and unable to hold much of the services for mankind. The repeated forest fires have been accelerating the loss of plants and animal diversity from the ecosystems. The need of the hour is therefore to adapt measures which will be people-centric and transparent and will be able to respond to short term risks. Besides, adaptation measures are required to address the present state of limitations and uncertainties about climate change impacts on forests and forest-dependent communities, in order that improved management and policy measures for wise/intelligent adaptation to climate changes are made sustainable.

\section{Acknowledgements}

This research was financially sponsored by the Department of Environment, Forests and Climate Change, Government of Mizoram (Grant No. B. 28011/22/ 2016-PCCF/310). Dr. K. Kire, Additional Principal Chief Conservator of Forests \& Nodal Officer, Climate Change Cell, Government of Mizoram provided the needed logistic support for carrying out the work. Mr. Anudip Gogoi and Ms Alice Kenye assisted in various ways during the field visit and data compilation. Ms K. Lalhmingsangi helped in translating the questionnaire into local (Mizo) language and for correct interpretation of facts. We also acknowledge the immense help received from key informants, villagers and are grateful to all respondents who spared their valuable time during the survey. 


\section{Conflicts of Interest}

The authors declare that they have no conflict of interest.

\section{Authors' Contribution}

UKS designed the study, obtained the funding, supervised the study and drafted the paper, SLS conducted field study, analyzed the data, made the first draft of the paper; SSS analyzed the data, helped in statistics, improved language component and wrote the first draft, LND, LNT, ASD and JZ helped in drafting of the paper at various stages. All the authors have revised the manuscript and approved.

\section{References}

[1] Hansen, J., Sato, M., Ruedy, R., Lo, K., Lea, D.W. and Madina-Elizade, M. (2006) Global Temperature Change. Proceedings of the National Academy of Sciences of the United States of America, 103, 14288-14293. https://doi.org/10.1073/pnas.0606291103

[2] Morin, X., Fahse, L., Jactel, H., Scheren-Lorenzen, M., Garcia-Valdes, R. and Bugmann, H. (2018) Long-Term Response of Forest Productivity to Climate Change Is Mostly Driven by Tree Species Composition. Scientific Reports, 8, 5627. https://doi.org/10.1038/s41598-018-23763-y

[3] Buechling, A., Martin, P.H. and Canham, C.D. (2017) Climate and Competition Effects on Tree Growth in Rocky Mountain Forests. Journal of Ecology, 105, Article ID: 12782. https://doi.org/10.1111/1365-2745.12782

[4] Ionescu, C., Klein, R., Hinkel, J., Kavi Kumar, K. and Klein, R. (2009) Towards a Formal Framework of Vulnerability to Climate Change. Environmental Modeling Assessment, 14, 1-16. https://doi.org/10.1007/s10666-008-9179-X

[5] Yengoh, G.T., Tchuinte, A., Armah, F.A. and Odoi, J.O. (2010) Impact of Prolonged Rainy Seasons on Food Crop Production in Cameroon. Mitigation and Adaptation of Global Change, 15, 825-841. https://doi.org/10.1007/s11027-010-9241-2

[6] Sahoo, U.K, Lalremruata, J., Jeeceelee, L., Lalremruati, J.H., Lalliankhuma, C. and Lalramnghinglova, H. (2010) Utilization of Non-Timber Forest Products by the Tribal around Dampa Tiger Reserve in Mizoram. The Bioscan, 3, 721-729.

[7] Sahoo, U.K., Lalremruata, J., Lalramnghinglova, H. Lalremruati, J.H. and Lalliankhuma, C. (2010) Livelihood Generation through Non-Timber Forest Products by Rural Poor in and around Dampa Tiger Reserve in Mizoram. Journal of Non-Timber Forest Products, 17, 147-161.

[8] Sahoo, U.K., Jeeceelee, L., Lalremruata, J.H. and Lalramnghinglova, H. (2012) Diversity of Non-Timber Forest Products of Plant Origin, Use and Local Dependence in Mizoram, North-East India. Journal of Non-Timber Forest Products, 19, 261-268.

[9] IPCC (2007) Climate Change 2007: The Physical Science Basis. In: Solomon, S., Qin, D., Manning, M., Chen, Z., Marquis, M., Averyt, K.B., Tignor, M. and Miller, H.L., Eds., Contribution of Working Group I to the Fourth Assessment Report of the Intergovernmental Panel on Climate Change, Cambridge University Press, Cambridge, United Kingdom and New York, NY, USA.

[10] Bellard, C., Bertelsmeier, C., Leadley, P., Thuiller, W. and Courchamp, F. (2014) Impact of Climate Change on the Future of Biodiversity. Ecology Letter, 15, 365-377. https://doi.org/10.1111/j.1461-0248.2011.01736.x 
[11] Huong, N.T.L., Bo, Y.S. and Fagad, S. (2018) Economic Impact of Climate Change on Agriculture Using Ricardian Approach: A Case of Northwest Vietnam. Journal of South Society of Agricultural Sciences, In Press. https://doi.org/10.1016/j.jssas.2018.02.006

[12] Fisher, J.A., Patenaude, G., Giri, K., Lewis, K., Meir, P., Pinha, P., Rounsevell, M.D.A. and William, M. (2014) Understanding the Relationship between Ecosystem Services and Poverty Alleviation: A Conceptual Framework. Ecosystem Services, 7, 34-45. https://doi.org/10.1016/j.ecoser.2013.08.002

[13] Dave, R., Tompkins, E.L. and Schreekenberg, K. (2017) Forest Ecosystem Services Derived by Smallholder Farmers in Northwestern Madagascar: Storm Hazard Mitigation and Participation in Forest Management. Forest Policy and Economics, 84, 72-82. https://doi.org/10.1016/j.forpol.2016.09.002

[14] McGill, N. (2016) Vulnerable Populations at Risk from Effects of Climate Change: Public Health Working to Find Solutions. The Nation's Health, 46, 1-14.

[15] Nhemachena, C. and Hassan, R.M. (2007) Micro-Level Analysis of Farmers' Adaptation to Climate Change in Southern Africa. IFPRI Research Paper 00714, 15-17.

[16] De Zoysa, M. and Inoue, M. (2014) Climate Change Impacts, Agroforestry Adaptation and Policy Environment in Sri Lanka. Open Journal of Forestry, 4, 439-456. https://doi.org/10.4236/ojf.2014.45049

[17] Bryan, E., Ringler, C., Okoba, B., Rancoli, C., Silverstri, S. and Herrero, M. (2013) Adapting Agriculture to Climate Change in Kenya: Household Strategies and Determinants. Journal of Environmental Management, 114, 26-35.

https://doi.org/10.1016/j.jenvman.2012.10.036

[18] Baul, T.K., Atique Ullah, K.M., Tiwari, R.K. and McDonald Morag, A. (2013) People's Local Knowledge of Climate Change in the Middle Hills of Nepal. Indian Journal of Traditional Knowledge, 12, 585-595.

[19] Bele, M.Y., Tiani, A.M., Somorin, O.A. and Sonwa, D.J. (2013) Exploring Vulnerability and Adaptation to Climate Change of Communities in the Forest Zone of Cameroon. Climate Change, 119, 875-889. https://doi.org/10.1007/s10584-013-0738-Z

[20] Okonya, J.S., Syndikus, K. and Kroschei, J. (2013) Farmers' Perception of and Coping Strategies to Climate Change: Evidence from Six Agro-Ecological Zones of Uganda. Journal of Agricultural Sciences, 5, 252-263.

[21] Onyekuru, A.N. and Marchant, R. (2014) Climate Change Impact and Adaptation Pathways for Forest Depended Livelihood Systems in Nigeria. African Journal of Agricultural Research, 9, 1819-1832.

[22] Jin, J., Gao, Y., Wang, X. and Pham, K.N. (2015) Farmers' Risk Preferences and Their Climate Change Adaptation Strategies in the Yongqiao District, China. Land Use Policy, 47, 365-372. https://doi.org/10.1016/j.landusepol.2015.04.028

[23] Fadina, A.M.R. and Barjolle, D. (2018) Farmers' Adaptation Strategies to Climate Change and Their Implications in the Zou Department of South Berlin. Environments, 5, 15. https://doi.org/10.3390/environments5010015

[24] Arjunan, M., Puyravaud, J.P. and Davidar, P. (2005) The Impact of Resource Collection by Local Communities on the Dry forests of the Kalkad-Mundanthurai Tiger Reserve. Tropical Ecology, 46, 135-144.

[25] Kelkar, U., Narual, K.K., Sharma, V.P. and Chandna, V. (2008) Vulnerability and Adaptation to Climate Variability and Water Stress in Uttarakhand State, India. Global Environmental Change, 18, 564-574. https://doi.org/10.1016/j.gloenvcha.2008.09.003 
[26] Banerjee, R.R. (2014) Farmers' Perception of Climate Change, Impact and Adaptation Strategies: A Case Study of Four Villages in the Semi-Arid Regions of India. Natural Hazards, 75, 2829-2845.

[27] Vardan, R.J. and Kumar, P. (2014) Indigenous Knowledge about Climate Change: Validating the Perceptions of Dry Land Farmers in Tamil Nadu. Indian Journal of Traditional Knowledge, 13, 390-397.

[28] Chaudhary, J.S., Shukla, G., Prabhakar, C.S., Maurya, S., Das, B. and Kumar, S. (2012) Assessment of Local Perceptions on Climate Change and Coping Strategies in Chotanagpur Plateau of Eastern India. Journal of Progressive Agriculture, 3, 8-15.

[29] Joshi, A.K. and Joshi, P.K. (2011) A Rapid Inventory of Indicators of Climate Change in the Middle Himalaya. Current Science, 100, 831-832.

[30] Chaudhary, P. and Bawa, K.S. (2011) Local Perceptions of Climate Change Validated by Scientific Evidence in the Himalayas. Biological Letter, 7, 767-770. https://doi.org/10.1098/rsbl.2011.0269

[31] Dey, T., Pala, N.A., Shukla, G., Pal, P.K. and Chakravarty, S. (2017) Perception on Impact of Climate Change on Forest Ecosystem in Protected Area of West Bengal, India. Journal of Forest and Environmental Science, 33, 1-7. https://doi.org/10.7747/JFES.2017.33.1.1

[32] IMD (2013) State Level Climate Change in India. Indian Meteorological Department (IMD), Government of India.

[33] ISFR (2017) India State of Forest Report, Forest Survey of India.

[34] Frechtling, J., Sharp, L. and Westat (1997) User-Friendly Handbook for Mixed Method Valuations. National Science Foundation.

[35] Kerlinger, F.N. (1973) Foundations of Behavioral Research. Holt, Rinehart and Winston Inc., New York.

[36] Mings, L. (2008) Determination of Knowledge, Attributes and Practices in Climate Change Issue. Environmental Tourism Consulting, St. Johns, Antigua, 1-12.

[37] Falaki, A.A., Akangbe, J.A. and Ayinde, O.E. (2013) Analysis of Climate Change and Rural Farmer's Perception in North Central Nigeria. Journal of Human Ecolo$g y, 43,133-140$. https://doi.org/10.1080/09709274.2013.11906619

[38] Baidya, S.K., Shrestha, M.L. and Sheikh, M.M. (2008) Trends in Daily Climatic Extremes of Temperature and Precipitation in Nepal. Journal of Hydrology and Meteorology, 5, 38-51.

[39] Nile, M.T. and Mueller, N.D. (2016) Farmer Perceptions of Climate Change: Associations with Observation Temperature and Precipitation Trends, Irrigation and Climate Beliefs. Global Environmental Change, 39, 133-142. https://doi.org/10.1016/j.gloenvcha.2016.05.002

[40] Wolka, E. and Zeleke, G. (2016) Understanding Farmers Perception on Climate Change and Adaptation Strategies in Karetha Watershed, Omo-Gibe Basin, Ethipoia. Asian Journal of Earth Science, 10, 22-32. https://doi.org/10.3923/ajes.2017.22.32

[41] Smith, W.J., Liu, Z., Sati, A.S. and Chief, K. (2014) Climate Change Perception, Observation and Policy Support in Rural Nevada: A Comparative Analysis of Native Americans, Non-Native Ranchers and Farmers and Mainstream America. Environmental Science Policy, 42, 101-122. https://doi.org/10.1016/j.envsci.2014.03.007

[42] Kabir, M.I., Rahman, M.B., Smith, W., Lush, M.A.F., Azim, S. and Milton, A.H. (2016) Knowledge and Perception about Climate Change and Human Health: 
Findings from Baseline Survey among Vulnerable Communities in Bangladesh. BMC Public Health, 16, 266. https://doi.org/10.1186/s12889-016-2930-3

[43] Sahoo, U.K., Singh, S.L., Nundanga, L., Nuntluanga, L., Devi, A.S. and Zothanzama, J. (2018) Climate Change Impacts on Forest and Its Adaptation Study in Mizoram. Technical Report, Mizoram University, Aizawl (Mizoram), 32.

[44] Bostrum, A., Morgan, M.G., Fischoff, B. and Read, D. (1994) What Do People Know about Global Climate Change? 1. Mental Models. Risk Analysis, 14, 959-970. https://doi.org/10.1111/j.1539-6924.1994.tb00065.x

[45] Leiserowitz, A. (2006) Climate Change Risk Perception and Policy Preferences: The Role of Affect, Imagery, and Values. Climate Change, 77, 45-72. https://doi.org/10.1007/s10584-006-9059-9

[46] Patt, A. and Schroter, D. (2008) Perceptions of Climate Risk in Mozambique: Implications for the Success of Adaptation Strategies. Global Environmental Change, 18, 458-467. https://doi.org/10.1016/j.gloenvcha.2008.04.002

[47] Salau, E.S., Onuk, E.G. and Ibrahim, A. (2012) Knowledge, Perception and Adaptation Strategies to Climate Change among Farmers in Southern Agricultural Zone of Nasarawa State, Nigeria. Journal of Agricultural Extension, 16, 199-211.

[48] Gukurume, S. (2013) Climate Change, Variability and Sustainable Agriculture in Zimbabwe's Rural Communities. Russian Journal of Agricultural and Socio-Economic Sciences, 2, 89-100.

[49] Chhetri, N.B. and Easterling, W.E. (2010) Adapting to Climate Change: Retrospective Analysis of Climate Technology Interaction in the Rice Based Farming System of Nepal. Annals of Association of American Geographers, 100, 1-21. https://doi.org/10.1080/00045608.2010.518035

[50] Dey, P. and Sarkar, A.K. (2011) Revisiting Indigenous Farming Knowledge of Jharkhand (India) for Conservation of Natural Resources and Combating Climate Change. Indian Journal of Traditional Knowledge, 11, 71-79. 